\title{
DIAGNÓSTICO DO ESTADO NUTRICIONAL DE N EM PORTA-ENXERTOS DE CITROS, UTILIZANDO-SE DE TEORES FOLIARES DE CLOROFILA ${ }^{1}$
}

\author{
ANTÔNIO DECARLOS NETO², DALMO LOPES DE SIQUEIRA3, \\ PAULO ROBERTO GOMES PEREIRA ${ }^{3}$ E VICTOR HUGO ALVAREZ V. ${ }^{4}$
}

\begin{abstract}
RESUMO - Objetivou-se, neste trabalho, avaliar os teores foliares de clorofila total $(\mathrm{a}+\mathrm{b})$ em porta-enxertos de citros cultivados em tubetes, como índices no diagnóstico do estado nutricional de N, de acordo com adição das doses de N $(0 ; 400 ; 800 ; 1.600 ; 3.200$ e 4.800 $\mathrm{mg} / \mathrm{dm}^{3}$ de N no substrato). Os teores foliares de clorofila total apresentaram alta correlação positiva com a altura, diâmetro do caule, massa da matéria seca da parte aérea e raízes, área foliar e teor de $\mathrm{N}_{-} \mathrm{NO}_{3}$ da parte aérea dos porta-enxertos, indicando a possibilidade de serem utilizados como índices para o diagnóstico de $\mathrm{N}$ em porta-enxertos cultivados em tubetes. Aos 120 dias após a semeadura, os teores foliares máximos de clorofila total dos porta-enxertos 'Tangelo-Orlando', 'Cravo', 'Volkameriano', 'Cleópatra' e 'Sunki' ocorreram quando foram aplicadas as doses $1.461 ; 2.386 ; 2.4941 .444 ;$ e $2.284 \mathrm{mg} / \mathrm{dm}^{3}$ de $\mathrm{N}$ no substrato, respectivamente. Os teores foliares adequados de clorofila total do porta-enxerto 'Tangelo-Orlando' devem estar compreendidos na faixa de 1,80 a 3,00 mg de clorofila total $/ \mathrm{dm}^{2}$ de folha, aos 120 dias após a semeadura. Para o limoeiro- 'Cravo' esta faixa deve ser de 2,46 a 3,94 mg de clorofila total $/ \mathrm{dm}^{2} \mathrm{de}$ folha, sendo que, para o limoeiro-'Volkameriano', esta faixa deve ser de 2,27 a 4,23 mg de clorofila total $/ \mathrm{dm}^{2} \mathrm{de}$ folha. Para a tangerineira 'Cleópatra', a faixa adequada dos teores foliares de clorofila total deve ser de 3,29 a 4,00 mg de clorofila total $/ \mathrm{dm}^{2}$ de folha, sendo que, para a tangerineira-'Sunki', esta faixa deve ser de 1,80 a $3,16 \mathrm{mg}$ de clorofila total $/ \mathrm{dm}^{2}$ de folha.
\end{abstract}

Termos para indexação: citros, viveiro, diagnose, teor de clorofila, adubação, nutrição, nitrogênio

\section{DIAGNOSTIC OF NITROGEN NUTRITIONAL LEVEL IN CITRUS ROOTSTOCKS USING FOLIAR CHLOROPHYLL CONTENT}

\begin{abstract}
The objective of this work was to evaluate chlorophyll content $(\mathrm{a}+\mathrm{b})$ on 'Cravo', 'Cleópatra', 'Sunki', 'Volkameriano' and 'Tângelo Orlando' rootstocks in tubes using as indicator on diagnosis by increasing $\mathrm{N}$ doses $(0 ; 400 ; 800 ; 1,600 ; 3,200 ; 4,800 \mathrm{mg}$ $\mathrm{N} / \mathrm{dm}^{3}$ of substrate). The chlorophylls content presented righ positive correlation to height, diameter, aerial portion and roots dry matter mass, foliar area and $\mathrm{NO}_{3}-\mathrm{N}$ content for aerial portion, indicating that the total chlorophyll content can be used as indicator to diagnose $\mathrm{N}$ in citrus rootstocks cultivated in tubes. The maximum chlorophylls content estimated in rootstocks 'Tangelo-Orlando', 'Cravo', 'Volkameriano', 'Cleópatra' e 'Sunki' occurred in doses 1,461; 2,386;2,494; 1,444; and 2,284 (mg N/dm³ of substrate), respectively. Total foliar chlorophyll content adequate for rootstocts of 'Tangelo Orlando' showed to be placed between 1.80 to $3.00 \mathrm{mg}$ of total chlorophyll/ $\mathrm{dm}^{2}$ of leaf at 120 days after sowing, for lemon 'Cravo' between 2.46 to 3.94 while the 'Volkameriano' showed to be placed between 2.27 to $4.23 \mathrm{mg}$ of total chlorophyll $/ \mathrm{dm}^{2}$ of leaf. Adequate values for foliar contents for total chlorophyll for Cleopatra tangerine showed to be 3.29 to $4.00 \mathrm{mg}$ of total chlorophyll/ $\mathrm{dm}^{2}$ of leaf while for 'Sunki' tangerine the values showed to be 1.80 to 3.16 $\mathrm{mg}$ of total chlorophyll/ $\mathrm{dm}^{2}$ of leaf.
\end{abstract}

Index terms: citrus, nursery, diagnostic, chlorophyll content, fertilizing, nutrition, nitrogen

\section{INTRODUÇÃO}

A semeadura de porta-enxertos de citros em tubetes exige adubações de cobertura com $\mathrm{N}$ para a complementação da fertilidade natural do substrato, favorecendo, assim, o rápido crescimento dos porta-enxertos na fase de sementeira (Carvalho \& Souza, 1996; Decarlos Neto et al., 1994).

Pesquisas realizadas com porta-enxertos de citros na fase de viveiro (Carvalho \& Souza, 1996; Carvalho, 1994; Maust \& Williamson, 1994) têm mostrado exigência de $\mathrm{N}$ diferenciada entre os porta-enxertos. Entretanto, há carência de informações sobre métodos não destrutivos, que auxiliem no diagnóstico do estado nutricional de $\mathrm{N}$ em porta-enxertos de citros cultivados em tubetes.

A fotossíntese consiste no processo pelo qual as plantas verdes transformam a energia radiante do sol em energia química. A molécula de clorofila presente nos cloroplastos absorve a energia radiante, ativando o sistema fotossintético. O nitrogênio participa na composição estrutural da molécula de clorofila na porção porfirina, nos anéis tetrapirrólicos (Taiz \& Zeiger, 1991; Marschner, 1995). Experimentos realizados com diversas culturas indicam que existe correlação positiva entre os teores foliares de clorofila, determinados em laboratório por espectrofotômetro ou utilizando medidores indiretos de clorofila, e as características de crescimento de plantas (Shadchina \& Dmitrieva, 1995; Neilsen et al., 1995; Lopez-Canareno et al., 1994; Minotti et al., 1994.

1 (Trabalho 021/2001). Recebido: 16/01/2001. Aceito para publicação: 14/11/2001. Apoio finaceiro do CNPq. Extraído da Dissertação apresentada pelo primeiro autor junto à Universidade Federal de Viçosa (UFV), para obtenção do título de Mestre.

2 Mestrando em Agronomia - Depto. de Fitotecnia UFV, Viçosa (MG) - decarlos@zipmail.com

3 Prof. Dr. Depto. Fitotecnia UFV, Viçosa (MG) - CEP: 36570-000.

4 Prof. Dr. Depto. Solos UFV, Viçosa (MG) - CEP: 36570-000. 
Shadchina \& Dmitrieva (1995) determinaram os teores foliares de clorofila em plantas de trigo pelo método de Arnon (1949), concluindo que os teores foliares de clorofila podem ser utilizados como característica apropriada para a determinação do $\mathrm{N}$ absorvido pelas plantas.

Como vantagens de se medir os teores foliares de clorofila no diagnóstico do estado nutricional de N, Malavolta et al. (1998) descreveram que o teor foliar de clorofila indica o nível adequado de $\mathrm{N}$, e não é afetado pelo consumo de luxo do elemento em questão, visto que a planta não produz clorofila além do que necessita. $\mathrm{O}$ monitoramento do verde da folha pode sinalizar uma deficiência de $\mathrm{N}$ com antecedência, podendo essa deficiência ser corrigida com adubações nitrogenadas.

Em plantas cítricas, a determinação dos teores foliares de clorofila para auxiliar no diagnóstico do estado nutricional de $\mathrm{N}$, vem sendo pouco utilizada. Assim, foi objetivo deste experimento determinar os teores foliares de clorofila total $(a+b)$ dos portaenxertos de citros para fins de diagnose do estado nutricional de $\mathrm{N}$, correlacionando esses teores com as características de crescimento e teores de $\mathrm{N}$ dos porta-enxertos.

\section{MATERIAL E MÉTODOS}

O experimento foi conduzido em casa de vegetação no Setor de Fruticultura da Universidade Federal de Viçosa (UFV), em Viçosa - MG, iniciado em setembro de 1995. As sementes foram extraídas de frutos maduros de plantas-matrizes dos portaenxerto Citrus limonia Osbeck, cv Cravo (Cr); Citrus reshni Hort. ex Tan., cv Cleópatra (Cl); Citrus sunki Hort. ex. Tan., cv Sunki (Sk); Citrus volkameriana Hort. ex Tan., cv Volkameriano (Vk); e Citrus paradisi Macf. x Citrus reticulata Blanco, cv Tangelo-Orlando (To). Os porta-enxertos foram semeados e cultivados num substrato composto de esterco de bovino + vermiculita expandida + terriço (1:1:1), enriquecido com $1,28 \mathrm{~kg} /$ $\mathrm{m}^{3}$ de $\mathrm{P}_{2} \mathrm{O}_{5}$ no substrato, sendo utilizados como recipientes tubetes plásticos com diâmetro interno de $26 \mathrm{~mm}$ e comprimento de $126 \mathrm{~mm}$.

Foi utilizado o delineamento experimental em blocos casualizados, em esquema de parcelas subdivididas, com cinco repetições e unidade experimental com 32 plantas, sendo 12 úteis. As parcelas foram compostas dos cinco diferentes porta-enxertos. As subparcelas foram compostas de seis doses de $\mathrm{N}(0 ; 400$; $800 ; 1.600 ; 3.200$ e $4.800 \mathrm{mg} / \mathrm{dm}^{3}$ de N no substrato). As doses de $\mathrm{N}$ foram parceladas em oito aplicações de cobertura com uréia, em intervalos de sete dias, via água de irrigação. Em cada adubação, foram aplicados $5 \mathrm{ml}$ de solução por tubete (com 40 $\mathrm{cm}^{3}$ de substrato). As adubações foram iniciadas após o desbaste das plantas nos tubetes, aos 63 dias após a semeadura.

Avaliaram-se: altura, diâmetro do caule, área foliar, massa da matéria seca da parte aérea e da raiz, teor de N-total, N-orgânico e $\mathrm{N}-\mathrm{NO}_{3}$ da matéria seca da parte aérea e teor de clorofila total $(\mathrm{a}+\mathrm{b})$ da folha dos porta-enxertos, aos 120 dias após a semeadura.

$\mathrm{O}$ teor foliar de clorofila total foi determinado pelo método de laboratório desenvolvido por Arnon (1949), sendo amostrados 25 discos $\left(637,9 \mathrm{~mm}^{2}\right)$ de limbo de folhas completamente desenvolvidas e maduras $\left(3^{\mathrm{a}}\right.$ ou $4^{\mathrm{a}}$ folha a partir do ápice da planta). O N-orgânico foi dosado pelo método de Nessler após a digestão sulfúrica. $\mathrm{O} \mathrm{N}-\mathrm{NO}_{3}$ foi dosado pelo método do ácido salicílico, sendo que o teor de $\mathrm{N}$-total foi obtido a partir da soma do teor do N-orgânico com o teor de $\mathrm{N}^{-\mathrm{NO}_{3}}$.

Os dados coletados foram submetidos à análise de variância, e os fatores de variação foram testados pelo teste $\mathrm{F}$ (significância de $5 \%$ e $1 \%$ ). Foram estabelecidos contrastes ortogonais que analisaram as diferenças do híbrido 'TangeloOrlando' com os demais porta-enxertos [(To) vs. $(\mathrm{Cr}+\mathrm{Vk}+\mathrm{Cl}+\mathrm{Sk})]$, diferenças dos limoeiros com as tangerineiras $[(\mathrm{Cr}+\mathrm{Vk})$ vs. $(\mathrm{Cl}+\mathrm{Sk})]$, diferenças entre os limoeiros $[(\mathrm{Cr})$ vs. $(\mathrm{Vk})]$ e diferenças entre as tangerineiras $[(\mathrm{Cl})$ vs. (Sk)]. Os efeitos da variável quantitativa (doses de $\mathrm{N}$ ) foram submetidos ao ajuste de equações de regressão, sendo que a significância dos coeficientes das equações de regressão ajustadas foi testada pelo teste F, calculado e corrigido conforme Alvarez V. (1985).

\section{RESULTADOS E DISCUSSÃO}

\section{Teores foliares de clorofila total $(a+b)$ dos porta-enxertos}

A Tabela 1 mostra que o híbrido 'Tangelo-Orlando' apresentou 2,01 $\mathrm{mg}$ de clorofila total $/ \mathrm{g}$ de folha, sendo esse teor significativamente superior $(\mathrm{P}<0,05)$ aos teores foliares de clorofila total dos demais porta-enxertos, conforme o resultado do contraste que comparou este híbrido com os demais portaenxertos.

Os teores foliares de clorofila total dos limoeiros- 'Cravo' e 'Volkameriano' foram semelhantes aos teores das tangerineiras'Cleópatra' e 'Sunki' (Tabela 1), onde este contraste não mostrou diferenças significativas. Não foi observada diferença significativa entre os teores foliares de clorofila total do limoeiro- 'Cravo' com o limoeiro-'Volkameriano'. Foi observado que os teores foliares de clorofila total da tangerineira- 'Cleópatra' (Tabela 1) foram significativamente superiores $(\mathrm{P}<0,01)$ aos da tangerineira'Sunki', conforme o resultado do contraste estabelecido.

Houve, de maneira geral, pouca variação nos teores foliares de clorofila total entre os porta-enxertos, aos 120 dias após a semeadura. Estes resultados estão de acordo com os encontrados por Esposti (2000), onde este autor constatou pouca variação nos teores foliares de clorofila total nos diferentes porta-enxertos testados.

\section{Correlações do teor de clorofila com o crescimento e teores de $\mathrm{N}$ dos porta-enxertos}

Os teores foliares de clorofila total dos porta-enxertos apresentaram correlações positivas e significativas com a altura, diâmetro do caule, área foliar, massa da matéria seca da parte aérea e das raízes e teores de $\mathrm{N}-\mathrm{NO}_{3}$ da parte aérea, dos portaenxertos, conforme apresentado na Tabela 2; não sendo observadas correlações significativas com os teores foliares de $\mathrm{N}$-total e N-orgânico. As correlações entre os teores foliares de clorofila total com as características de crescimento dos portaenxertos ocorreram, certamente, devido ao fato de a molécula de clorofila estar contida nos cloroplastos, absorvendo a energia radiante e ativando o sistema fotossintético (Taiz e Zeiger, 1991; Marschner, 1995).

As correlações observadas indicam que os teores foliares de clorofila total dos porta-enxertos avaliados têm potencial de utilização no diagnóstico de $\mathrm{N}$. Com o monitoramento do verde da folha dos porta-enxertos, utilizando-se dos teores foliares de clorofila, pode-se detectar, com antecedência, uma possível 
TABELA 1 - Teores médios ${ }^{(1)}$ de clorofila total $(\mathrm{a}+\mathrm{b})$ dos porta-enxertos 'Cravo', 'Cleópatra', 'Sunki', 'Volkameriano' e 'Tangelo Orlando', medidos aos 120 dias após a semeadura.

\begin{tabular}{|c|c|c|}
\hline \multirow[t]{2}{*}{ Porta-enxertos } & \multicolumn{2}{|c|}{ C lo ro fila to ta $1(\mathrm{a}+\mathrm{b})$} \\
\hline & ( $\mathrm{mg}$ de clorofila $/ \mathrm{dm}^{2} \mathrm{de}$ folha) & (mg de clorofila/g de folha) \\
\hline 'Tangelo O rlando' & 3,21 & 2,01 \\
\hline 'C ravo' & 3,04 & 1,84 \\
\hline 'V olk ame riano' & 3,06 & 1,87 \\
\hline 'C leóp a tra' & 3,15 & 1,94 \\
\hline 'S unki' & 2,50 & 1,47 \\
\hline
\end{tabular}

${ }^{1}$ : Médias das doses de $\mathrm{N}$.

TABELA 2 - Coeficientes de correlação linear simples entre os teores de clorofila total $(a+b)$ com as características de crescimento e teores de $\mathrm{N}$-total, N-orgânico e $\mathrm{N}-\mathrm{NO}_{3}$ da matéria seca da parte aérea dos porta-enxertos, aos 120 dias após a semeadura.

\begin{tabular}{lcc}
\hline C aracterísticas & (mg de clorofila/g de folha $)$ & $\left(\mathrm{mg}\right.$ de clorofila/dm ${ }^{2}$ de folha $)$ \\
\hline A ltura & $0,89^{* *}$ & $0,87 * *$ \\
Diâmetro & $0,85^{*}$ & $0,81^{*}$ \\
M S (parte aérea) & $0,97^{* *}$ & $0,96^{* *}$ \\
M S (raiz) & $0,84^{*}$ & $0,81^{*}$ \\
Á rea foliar & $0,94^{* *}$ & $0,91^{* *}$ \\
N - total & $0,58^{\mathrm{NS}}$ & $0,56^{\mathrm{NS}}$ \\
$\mathrm{N}$ - orgânico & $0,56^{\mathrm{NS}}$ & $0,53^{\mathrm{NS}}$ \\
$\mathrm{N}-\mathrm{NO}_{3}$ & $0,96^{*}$ & $0,97 *$ \\
\hline
\end{tabular}

Ns e $^{* *}, *$ não-significativos e significativo a $1 \%$ e $5 \%$, respectivamente, pelo teste t.

TABELA 3 - Faixa $^{(1)}$ do teor adequado de clorofila total $(\mathrm{a}+\mathrm{b})$ de folhas dos porta-enxertos, determinada aos 120 dias após a semeadura.

\begin{tabular}{lc}
\hline Porta-enxertos & C lorofila to tal $(\mathrm{a}+\mathrm{b})$ \\
\hline & $(\mathrm{mg}$ clorofila/dm² de folha $)$ \\
'Tangelo O rlando' & $1,80-3,00$ \\
'C ravo' & $2,46-3,94$ \\
'Volkameriano' & $2,27-4,23$ \\
'C leópatra' & $3,29-4,00$ \\
'S unki' & $1,80-3,16$ \\
\hline
\end{tabular}

(1): Faixa determinada para $90 \%$ e $100 \%$ do crescimento máximo em altura dos porta-enxertos.

deficiência de N. Portanto, essa deficiência poderá ser corrigida antecipadamente com adubações nitrogenadas.

\section{Efeitos das doses de $\mathbf{N}$ sobre os teores foliares de clorofila total} $(a+b)$ dos porta-enxertos

Pelas equações de regressão (Figura 1), observa-se que, com o aumento das doses de $\mathrm{N}$ aplicadas, houve aumento significativo $(\mathrm{P}<0,01)$ nos teores foliares de clorofila total dos porta-enxertos, aos 120 dias após a semeadura. O teor foliar máximo de clorofila total dos porta-enxertos 'Cravo', 'Cleópatra', 'Sunki', 'Volkameriano' e 'Tangelo-Orlando' ocorreu quando foram aplicadas as doses de 2.386; 1.444; 2.284; 2.494 e $1.461 \mathrm{mg} /$ $\mathrm{dm}^{3}$ de $\mathrm{N}$ no substrato, respectivamente.

Na Tabela 3, estão apresentadas as faixas do teor adequado de clorofila total de folha dos porta-enxertos testados. Para o porta-enxerto 'Tangelo-Orlando', este teor deve estar compreendido na faixa de 1,80 a $3,00 \mathrm{mg}$ de clorofila total $/ \mathrm{dm}^{2}$ de folha. Para o limoeiro-'Cravo', esta faixa deve ser de 2,46 a 3,94 $\mathrm{mg}$ de clorofila total $/ \mathrm{dm}^{2}$ de folha, sendo que, para o limoeiro-
'Volkameriano', esta faixa deve ser de 2,27 a 4,23 mg de clorofila total $/ \mathrm{dm}^{2}$ de folha. Para a tangerineira- 'Cleópatra', a faixa adequada do teor de clorofila total deve ser de 3,29 a 4,00 mg de clorofila total $/ \mathrm{dm}^{2}$ de folha, sendo que, para a tangerineira-'Sunki', esta faixa deve ser de 1,80 a $3,16 \mathrm{mg}$ de clorofila total $/ \mathrm{dm}^{2}$ de folha.

O teor adequado de clorofila total de folha exibido pelos porta-enxertos apresentou diferenças, confirmando a necessidade de isolar a variedade a ser amostrada no diagnóstico de $\mathrm{N}$, conforme relataram Malavolta et al. (1998).

O teor adequado de clorofila total de folha dos portaenxertos, observados neste estudo, está próximo aos encontrados por Esposti (2000). Em termos práticos, esta faixa representa uma condição ótima de crescimento dos portaenxertos, podendo ser utilizada como critério da necessidade de $\mathrm{N}$ em porta-enxertos cultivados em tubetes.

Tendo conhecimento do teor adequado de clorofila na folha do porta-enxerto, existe a possibilidade de realizar o 


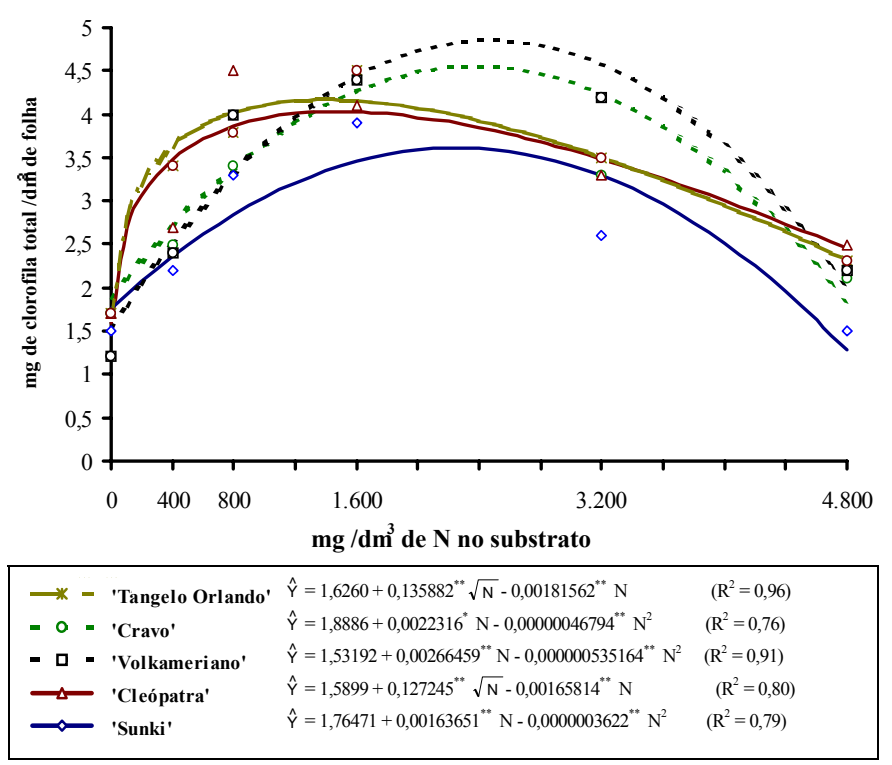

FIGURA 1 - Teores de clorofila total $(\mathrm{a}+\mathrm{b})$ de folhas dos portaenxertos 'Cravo', 'Cleópatra', 'Sunki', 'Volkameriano' e 'Tangelo-Orlando', medidos aos 120 dias após a semeadura, em função das doses de N.

monitoramento seqüencial da cor verde das folhas dos portaenxertos. Este monitoramento pode detectar, antecipadamente, uma deficiência de $\mathrm{N}$ nos porta-enxertos, sendo que esta deficiência poderá ser corrigida com antecedência.

\section{CONCLUSÕES}

1. Os teores foliares de clorofila total $(\mathrm{a}+\mathrm{b})$ se correlacionaram positivamente com as características de crescimento dos portaenxertos 'Cravo', 'Cleópatra', 'Sunki', 'Volkameriano' e 'Tangelo-Orlando', evidenciando que a determinação dos teores de clorofila total tem potencial no diagnóstico do estado nutricional de $\mathrm{N}$ desses porta-enxertos. $\mathrm{O}$ monitoramento seqüencial do verde da folha dos porta-enxertos, pelos teores de clorofila, pode sinalizar uma deficiência de $\mathrm{N}$ com antecedência.

2. O teor adequado de clorofila total $(\mathrm{a}+\mathrm{b})$ do porta-enxerto 'Tangelo Orlando', quando cultivado em tubetes, deve estar compreendido na faixa de 1,8 a 3,0 mg de clorofila $/ \mathrm{dm}^{2}$ de folha. Para o limoeiro- 'Cravo', esta faixa deve ser de 2,46 a 3,94 mg de clorofila $/ \mathrm{dm}^{2}$ de folha, sendo que para o limoeiro'Volkameriano', esta faixa deve ser de 2,27 a 4,23 mg de clorofila/ $\mathrm{dm}^{2}$ de folha. Para a tangerineira- 'Cleópatra', a faixa adequada do teor de clorofila total deve ser de 3,29 a 4,0 mg de clorofila/ $\mathrm{dm}^{2}$ de folha, sendo que, para a tangerineira- 'Sunki', esta faixa deve ser de 1,8 a 3,16 mg de clorofila/ $\mathrm{dm}^{2}$ de folha.

\section{REFERÊNCIAS BIBLIOGRÁFICAS}

ALVAREZ V, V.H. Avaliação da fertilidade do solo. Viçosa: UFV, $1985.75 \mathrm{p}$.
ARNON, D. I. Copper enzymes in isolated cloroplasts. Polyphenoloxidase in Beta vulgaris. Plant Physiology, Washington, v. 24, p.1-15, 1949.

CARVALHO, S. A. Manejo da adubação nitrogenada na produção de porta-enxertos cítricos em bandejas. 1994. 74f. Tese (Doutorado em Fitotecnia) - Escola Superior de Agricultura de Lavras, Lavras, 1994.

CARVALHO, S. A.; SOUZA, M. Doses e freqüência de aplicação de nitrato de potássio no crescimento do limoeiro- 'Cravo', e da tangerineira-'Cleópatra' em bandejas. Pesquisa Agropecuária Brasileira, Brasília, 31, n. 11, p. 815-822, 1996.

DECARLOS NETO, A.; DE GRANDI, A. J.; VICHIATO, M.; DO AMARAL, A. M.; SOUZA, M. Viabilização do uso de tubetes para obter o porta-enxerto de citros limoeiro- 'Cravo' com “solução de arranque". In: CONGRESSO BRASILEIRO DE FRUTICULTURA, 8. 1994, Salvador. Anais ... p.400-401 .

MAUST, B. E.; WILLIAMSON, J. G. Nitrogen nutrition of containerized citrus nursery plants. Journal of the american society for Horticultural Science, Alexandria, v, 119, n. 2, p. 95 $201,1994$.

LOPEZ-CANTARERO, I.; LORENTE, F. A.; ROMERO, L. Are chlorophylls good indicators of nitrogen and phosphorus levels. Journal of Plant Nutrition v.17, n. 6, p. 979-990, 1994.

MALAVOLTA, E.; VITTI, G. C.; OLIVEIRA, S. A. Avaliação do estado nutricional das plantas. Piracicaba: POTAFOS, 1998. 319 p.

MARSCHNER, H. Mineral nutrition of higher plants. 2. ed. Berna: International Potash Institute, 1995.680 p.

MINOTTI, P. L.; HALSETH, D. E.; SIECZKA, J. B. Field chlorophyll measurements to assess the nitrogen status of potato varieties. HortScience, Alexandria, v.29, n. 12, p. 1497-1500, 1994.

NEILSEN, D.; HOGUE, E. J.; NEIILSEN, G. H.; PARCHOMCHUK, P. Using SPAD-502 values to assess the nitrogen status of apple trees. HortScience, Alexandria, v. 30, n. 3 p. 508-512, 1995.

SHADCHINA, T. M.; DMITRIEVA, V. V. Leaf chlorophyll content as a possible diagnostic mean for the evoluation of plant nitrogen uptake fron the soil. Journal of Plant Nutrition, Montuello, v. 18, n. 7, p. 1427-1437, 1995.

ESPOSTI, M. D. D. Adubação e nutrição nitrogenada de portaenxertos de citros produzidos em citrovasos. 2000. $96 f$. Dissertação (Mestrado em Fitotecnia) - Universidade Federal de Viçosa. Viçosa, 2000.

TAIZ, L.; ZEIGER, E. Plant physiology. California, 1991. 565p. 